\title{
Molecular Variability among the Isolates of Sclerotium rolfsii Causing Stem and Pod Rot of Groundnut Collected from Karnataka, India
}

\author{
Poornima $^{1^{*}}$, Gururaj Sunkad ${ }^{1}$ and H. Sudini ${ }^{2}$ \\ ${ }^{1}$ Department of plant pathology, University of Agricultural Sciences, Raichur- 584 104, \\ Karnataka, India \\ ${ }^{2}$ International Crops Research Institute for the Semi-Arid Tropics Patencheru - 502324 \\ Telangana, India \\ *Corresponding author
}

\begin{abstract}
A B S T R A C T
Genetic variability among the 24 isolates of $S$. rolfsii was studied by using molecular markers like ITS-PCR and RAPD primers. Amplification of ITS region of rDNA with specific ITS1 and ITS4 universal primers produced approximately 650 to $700 \mathrm{bp}$ in all the isolates of the fungus confirmed that all the isolates obtained are Sclerotium rolfsii and

Keywords

Groundnut, Stem and pod rot, Sclerotium rolfsii, Molecular variability

\section{Article Info}

Accepted: 20 April 2018 Available Online: 10 May 2018 were sequenced. Identity of the isolates was confirmed with sequences of NCBI data base of $S$. rolfsii. Among the twenty four isolates, four random primers viz., UBC-467, UBC482, UBC-485 and UBC-489 generated reproducible polymorphism. Amplified products with all the primers have showed polymorphic and distinguishable banding pattern indicating the genetic diversity among all the isolates of S. rolfsii. A total of 342 reproducible and scorable polymorphic bands ranging approximately as low as $150 \mathrm{bp}$ to as high as $2000 \mathrm{bp}$ was generated with four primers among the twenty four isolates studied. All the twenty four isolates were grouped into three main clusters indicating there is genetic diversity in the isolates of $S$. rolfsii. Cluster I contained thirteen isolates, main cluster divided into two sub clusters, sub cluster I had eight isolates ( $\mathrm{Sr} 21, \mathrm{Sr} 20, \mathrm{Sr} 19$, $\mathrm{Sr} 18, \mathrm{Sr} 22, \mathrm{Sr} 24, \mathrm{Sr} 17$ and Sr23) and subcluster II had five isolates (Sr5, Sr2, Sr1, Sr6 and $\mathrm{Sr} 4)$. Main cluster II has two sub clusters, sub cluster I consisted of six isolates (Sr8, Sr3, Sr7, Sr12, Sr15 and Sr14) and in sub cluster II three isolates (Sr16, Sr10 and Sr13) were grouped. Cluster III consisted of two isolates ( $\mathrm{Sr} 9$ and $\mathrm{Sr} 11)$.
\end{abstract}

\section{Introduction}

Groundnut (Arachis hypogea L.) is a major legume and important oil seed crop in India which is grown over an area of 52.50 lakh ha with an annual production and productivity of 94.72 lakh tons and $1804 \mathrm{~kg} \mathrm{ha}^{-1}$ respectively (Anonymous, 2014). In Karnataka, it is grown to the extent of 7.25 lakh ha with 6.58 lakh tons production and with a productivity of 908 $\mathrm{kg} \mathrm{ha} \mathrm{h}^{-1}$ (Anonymous, 2014). The crop groundnut is affected by many diseases at different growth stages. Among the diseases, stem and pod rot caused by Sclerotium rolfsii Sacc. is emerging as a major problem and has become an economically important soil borne pathogen. Stem and pod rot disease is a potential threat to groundnut production and is 
of considerable economic significance for groundnut grown under irrigated conditions. Sclerotium rolfsii Sacc. is a soil borne pathogen common in tropical and sub-tropical regions of the world where high temperature coupled with high humidity is prevalent during the rainy season causing severe damage to the crop with yield losses of over 27 per cent (Ghewande et al., 2002). The symptoms of $S$. rolfsii include yellowing and wilting of branches, presence of white mycelial growth at collar region and production of mustard seed like sclerotia on infected parts (Asghari and Mayee, 1991). Studies of variability within the population in a geographical region are important because these also document the changes occurring in the population. Variability among $S$. rolfsii populations from different geographical regions was recorded by earlier workers (Harlton et al., 1995; Okabe et al., 1998; Sarma et al., 2002).

Molecular markers play a major role in analyzing genetic basis of genotypic variation among fungal population. Welsh and McClelland (1990) described a modification of the PCR procedure referred to as the randomly amplified polymorphic DNA (RAPD) marker technique that can be used to detect genetic polymorphisms in fungi. This technique can overcome the limitations of RFLPs such as they are relatively slow, expensive and laborious, as generally only a single locus can be analyzed with each RFLP reaction. RAPD technique differs from conventional PCR in that only a single primer which is derived from an arbitrary sequence is used for amplifying DNA (Perez Moreno et al., 2002). Hence the RAPD analysis being used as a powerful tool for the investigation of genetic relatedness and diversity among closely related strains and was found to be a valuable method for differentiating the genetic variability of $S$. rolfsii isolates (Saude et al., 2004). To understand the present plant disease situations and for effective management, it is essential to study as much as possible about the genetic variability in plant pathogenic fungi. The information on genetic variability among the groundnut isolates of $S$. rolfsii is limited. Thus, the present study was undertaken to assess the significant genetic variations by nucleic acid based marker techniques using ITS-PCR and RAPD.

\section{Materials and Methods}

A survey was conducted during kharif 2013 and 2014 in groundnut growing areas of Karnataka and groundnut plants infected with stem rot pathogen, S. rolfsii were collected. The pathogen, $S$. rolfsii was isolated from the stems of infected groundnut plants by tissue isolation method (Rangaswami and Mahadevan, 1999) on potato dextrose agar (PDA) medium.

\section{Cultural and morphological variability}

Eighty isolates collected from districts viz., Raichur, Ballari, Koppal, Gadag, Tumkur, Chitradurga, Gulburga and Yaadgir districts of Karnataka were studied for their cultural characters such as radial growth, colony morphology, production of sclerotial bodies and pattern of production of sclerotial bodies and morphological characters such as number of days taken to produce sclerotial bodies, colour of sclerotial bodies, number of sclerotial bodies produced per plate, diameter of sclerotial bodies and sclerotial texture were studied by using potato dextrose agar medium. Further, three isolates from each district of Karnataka were selected to study molecular variability among the isolates of $S$. rolfsii by using ITS region of rDNA and Random Amplified Polymorphic DNA (RAPD).

\section{Fungal cultures (S. rolfsii)}

Mycelial discs (5 $\mathrm{mm}$ diameter) of respective isolates of $S$. rolfsii from the periphery of an 
actively growing 7 days old culture on PDA were inoculated in to conical flask $(250 \mathrm{ml})$ containing $100 \mathrm{ml}$ PDB and flasks were incubated for three days at $27 \pm 2^{\circ} \mathrm{C}$ temperature. The mycelium grown on PDB was used for isolation of genomic DNA.

\section{Isolation of genomic DNA}

The DNA was extracted from 24 isolates of $S$. rolfsii. collected from eight districts of Karnataka from each district three isolates were selected. The extraction buffer used for Lysis method was composed of $(400 \mathrm{mM}$ TrisHcl, $60 \mathrm{mM}$ EDTA 1\% SDS, pH 8.0 and $150 \mathrm{mM} \mathrm{Nacl}$ ). Fresh or frozen mycelial mat (100 mg) was ground to fine powder with liquid nitrogen using pre-chilled mortar and pestle. The samples were then transferred to 2 $\mathrm{ml}$ Eppendorf tubes and $1 \mathrm{ml}$ of extraction buffer, $5 \mu \mathrm{l}$ of proteinase $\mathrm{K}$ was added to the samples and the samples are mixed by vortexing for $10 \mathrm{~min}$. The samples were centrifuged at $12,000 \mathrm{rpm}$ for $10 \mathrm{~min}$ at room temperature.

Take the supernatant add equal volume of Phenol: Chloroform: Isoamylalcohol (25:24:1). Centrifuged at $12000 \mathrm{rpm}$ for 10 min. at $4^{\circ} \mathrm{C}$ then take the supernatant, equal volume of chloroform: isoamyl alcohol (24:1) was added. Centrifuged at $12000 \mathrm{rpm}$ for 10 min. at room temperature, upper aqueous phase was transferred to a fresh tube. The upper aqueous layer was collected into Eppendorf and to this $3 \mu \mathrm{l}$ of RNase A (10 mg $\mathrm{ml}^{1}$ ) was added and the mixture was incubated at $37{ }^{\circ} \mathrm{C}$ for $30 \mathrm{~min}$. Finally $2 / 3^{\text {rd }}$ volume of ice cold isopropanol was added to the Eppendorf tubes. The contents were later mixed by tilting the tubes gently and the tubes were kept at $-20^{\circ} \mathrm{C}$ for $30 \mathrm{~min}$. to allow the DNA to precipitate. Later, the samples were centrifuged at $13000 \mathrm{rpm}$ for $20 \mathrm{~min}$. to collect the nucleic acid precipitate. The pellet was air dried for $10 \pm 15 \mathrm{~min}$ and suspend in $50 \mu 1 \mathrm{TE}$ buffer.

\section{Measurement of DNA concentration}

The quality and quantity of DNA was check by using Nanodrop ND 1000 the ratio of $260 / 280$ is 1.8 is obtained in all isolates.

\section{PCR amplification of ITS region}

PCR amplification of Internal Transcribed Spacers (ITS) region of rDNA was performed using universal primers ITS-1 (5' - TCC GTA GGT GGA CCT GCG G - 3') as forward primer and ITS-4 (5' - TCC TCC GCT TAT TGA TAT GC - 3') as reverse primer (White et al., 1990) in Eppendorf PCR master cycler. Amplification was carried out in $0.2 \mathrm{~mL}$ Eppendorf tubes with $25 \mu \mathrm{L}$ reaction mixture containing $2.5 \mu \mathrm{L}$ of $10 \mathrm{x}$ Taq buffer, $4 \mu \mathrm{L}$ of $25 \mathrm{mM} \mathrm{MgCl} 2,1.0 \mu \mathrm{L}$ of ITS1 primer (5 picomolar $/ \mu \mathrm{L}), 1.0 \mu \mathrm{L}$ of ITS-4 primer $(5$ picomolar $/ \mu \mathrm{L}$ ), $1 \mu \mathrm{L}$ of $5 \mathrm{mM}$ dNTP mix, 0.5

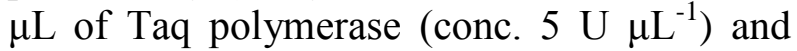
$12.00 \mu \mathrm{L}$ of Nuclease free water (Genei, Bangalore) and $3 \mu \mathrm{L}$ (100-200 ng) of DNA sample. The PCR amplification was carried out by $5 \mathrm{~min}$ of initial denaturation at $94^{\circ} \mathrm{C}$ followed by 35 cycles of denaturation of $94^{\circ} \mathrm{C}$ for $1 \mathrm{~min}$; annealing at $55^{\circ} \mathrm{C}$ for $2 \mathrm{~min}$; extension at $72^{\circ} \mathrm{C}$ for $1 \mathrm{~min}$ with final elongation at $72^{\circ} \mathrm{C}$ for $5 \mathrm{~min}$. Amplified PCR products were subjected to $1.2(\mathrm{w} / \mathrm{v})$ agarose gel using TBE (electrophoresis buffer, $40 \mathrm{mM}$ Tris 2mM EDTA, $\mathrm{pH}$ 8) containing ethidiumbromide $(0.5 \mu \mathrm{g} / \mathrm{ml})$. The size of the PCR product was estimated by comparison with known DNA marker of $1 \mathrm{~kb}$ DNA ladder. The banding profiles of ITS-PCR products were documented in gel documentation system.

\section{Sequencing of ITS region and in silico analysis}

The ITS region was sequenced from eighteen isolates belonging to different locations from Karnataka to confirm organism and to know 
the variability present in them. The PCR product was sequenced using forward and reverse primers at Chromos Biotech Ltd., Bengaluru. Homology search was done using BLAST algorithm available at the http://www.ncbi.nlm.nih.gov. Multiple alignments for homology search were performed using the Cluster W algorithm software and the phylogenetc tree was constructed (Patil, 2009).

\section{RAPD profiles through Polymerized Chain Reaction (PCR)}

Four random primers UBC-467, UBC-482, UBC-485 and UBC-489 were screened for generating polymorphism among the isolates under the study. The experiment was repeated thrice and results were reproducible. The Oligonucleotide primer sequences used in RAPD technique are given below:

PCR amplifications were carried out in $0.2 \mathrm{~mL}$ Eppendorf tubes with $25 \mu \mathrm{L}$ reaction mixture which consists of $2.5 \mu \mathrm{L}$ of $10 \mathrm{x}$ Taq buffer, $2.0 \mu \mathrm{L}$ of $25 \mathrm{mM} \mathrm{MgCl} 2,1.0 \mu \mathrm{L}$ of primer $(5$ picomolar/ $\mu \mathrm{l}), 1.0 \mu \mathrm{l}$ of $5 \mathrm{mM}$ dNTP mix, 0.5 $\mu \mathrm{L}$ of Taq polymerase enzyme (conc. $5 \mathrm{U} \mu \mathrm{L}$ 1) and $15.5 \mu \mathrm{L}$ of Nuclease free water (Genei, Bangalore) and $2.5 \mu \mathrm{L}$ (40-50 ng) of DNA sample. PCR amplification was carried out by 5 min of initial denaturation at $94^{\circ} \mathrm{C}$ followed by 40 cycles of denaturation of $94^{\circ} \mathrm{C}$ for 1 min; annealing at $37^{\circ} \mathrm{C}$ for $1 \mathrm{~min}$; extension at $72^{\circ} \mathrm{C}$ for $2 \mathrm{~min}$ with final elongation at $72^{\circ} \mathrm{C}$ for $5 \mathrm{~min}$.

Amplified PCR products were subjected to 1.5 per cent agarose gel electrophoresis with $1.0 \mathrm{x}$ TBE as running buffer. The banding patterns were visualized under UV trans-illuminator with ethidium bromide $\left(10 \mathrm{mg} \mathrm{mL}^{-1}\right)$ staining. The DNA banding profiles were documented in the gel documentation system (Alpha Innotech) and compared with $1 \mathrm{~kb}$ DNA ladder (Genei, Bangalore).

\section{Scoring and data analysis}

Each amplified band was considered as RAPD marker and recorded for all samples. Data was entered using a matrix in which all observed bands or characters were listed. The RAPD pattern of each isolate was evaluated, assigning character state ' 1 ' to all the bands that could be reproducible and detected in the gel and ' 0 ' for the absence of band. The binary data were thus obtained was used as an input for the construction of dendogram using the Unweighted Neighbourhood-joining method using the program DARwin 6.0 software (Perrier et al., 2003).

\section{Results and Discussion}

\section{Cultural variability of $S$. rolfsii isolates}

Based on radial mycelial growth among eighty isolates of $S$. rolfsii, seventy three isolates were found fast growing $(75-90 \mathrm{~mm})$, five isolates were moderate growing $(60-75 \mathrm{~mm})$ and two isolates were slow growing (45-60 $\mathrm{mm})$. Further, fifteen isolates showed compact growth and sixty five showed fluffy growth. With respect to pattern of production of sclerotial bodies, sixty four isolates produced sclerotial bodies scattered all over the plate, whereas thirteen at the periphery region and two at the centre region of Petriplate.

\section{Morphological variability of $S$. rolfsii isolates}

Based on colour of sclerotial bodies isolates were categorized into four groups, thirteen isolates produced dark brown, thirty three isolates light brown, four reddish brown and three isolates produced all the three coloured sclerotial bodies. Sixty two isolates were produced $(0-100)$ sclerotial bodies per plate, fourteen isolates produced 101-200 sclerotial bodies per plate, two isolates 201-300 sclerotial bodies per plate and isolate Sr15 
produced more than 300 sclerotial bodies per plate. Further, twenty five isolates produced 1$2 \mathrm{~mm}$ sized sclerotial bodies, forty five 0.5-1 $\mathrm{mm}$ and nine isolates produced more than 0.5 $\mathrm{mm}$ sized sclerotial bodies.

Identification of $S$. rolfsii isolates by ITS PCR

ITS-1 and ITS-4 primers were used for PCR amplification of ITS region of rDNA clusters (ITS-1, 5.8S and ITS-4 regions) of all twenty four isolates. Both the primers produced amplified product size of 650-700 bp in all the twenty four isolates indicating that all the isolates belong to genus Sclerotium (Fig. 1).

Amplification of the ITS region of rDNA produced an approximately $650-700$ bp fragment which is specific to $S$. rolfsii. Our results are in agreement with those of Adandonon et al., (2005) who studied genetic variation among $S$. rolfsii isolates of cowpea by using mycelial compatibility and ITS rDNA sequence data and obtained an amplification fragment of about $700 \mathrm{bp}$ which is specific for $S$. rolfsii. In the present study, all isolates gave the same size of the fragment that is $650-700 \mathrm{bp}$, which suggests that these isolates are the same species.

Harlton et al., (1995) screened a world-wide collection of $S$. rolfsii, using universal primer pairs ITS1-ITS4, ITS1-ITS2 and ITS3-ITS4, and revealed variation in ITS regions with 12 sub-groups. Sclerotium rolfsii and S. delphinii yielded a common unique band of about 720 bp.

\section{Nucleotide sequence accession number}

The BLAST data results revealed that the $S$. rolfsii isolates matched with the reference strains of NCBI results and identified as Sclerotium rolfsii and isolates were deposited in NCBI GenBank, Maryland, USA along with location of the isolates. Accession numbers obtained are: KT337415, KT337409, KT337424, KT337411, KT337413, KT337425, KT337414, KT337423, KT337420, KT337419, KT337421, KT337412, KT337426, KT337418, KT337422, KT337416, KT337410, and KT337417 (Table 1).

The BLAST data results revealed that the Sclerotium species matched with the reference strains of NCBI results and identified as Sclerotium rolfsii and represented in the phylogenetic tree (Fig. 3). Out of 18 isolates, all the isolates were distinct from one another in the cluster but identical to each other in homology and divergence with different nodes.

\section{Molecular diversity of $S$. rolfsii isolates by RAPD}

Among the twenty four isolates, four random primers viz., UBC-467, UBC-482, UBC-485 and UBC-489 generated reproducible polymorphism. Amplified products with all the primers have showed polymorphic and distinguishable banding pattern indicating the genetic diversity among all the isolates of $S$. rolfsii (Fig. 2).

A total of 342 reproducible and scorable polymorphic bands ranging approximately as low as $150 \mathrm{bp}$ to as high as $2000 \mathrm{bp}$ were generated with four primers among the twenty four isolates studied. The primer 467 amplified two unique fragments of approximately $350 \mathrm{bp}$ in $\mathrm{Sr} 1, \mathrm{Sr} 2, \mathrm{Sr} 5$ and 400bp in $\mathrm{Sr} 2$ isolate. Primer 482 amplified specific bands of $200 \mathrm{bp}$ in $\mathrm{Sr} 14, \mathrm{Sr} 15$ and 550 bp in $\mathrm{Sr} 4$ and Sr9, 1000bp in Sr7, Sr12, Sr14 and Sr15. Primer 485 amplified specific band of $500 \mathrm{bp}$ in $\mathrm{Sr} 13$ and $550 \mathrm{bp}$ in Sr18 primer, 489 amplified specific band of 450 bp in Sr10. However, $500 \mathrm{bp}$ fragment was absent in case of $\mathrm{Sr} 22$ compared to other isolates (Fig. 4). 


\section{RAPD profiles through Polymerized Chain Reaction (PCR)}

\begin{tabular}{|l|l|l|}
\hline Sl. No. & Primer & Primer Sequence $\left(\mathbf{5}^{\prime} \mathbf{3}^{\prime}\right)$ \\
\hline 1 & UBC-467 & GAG GAA GCTT \\
\hline 2 & UBC-482 & AGA CGG CCGG \\
\hline 3 & UBC-485 & AGC ACG GGCA \\
\hline 4 & UBC-489 & CTA TAG GCCG \\
\hline
\end{tabular}

Table.1 Eighteen isolates of Sclerotium rolfsii infecting groundnut along with their accession numbers

\begin{tabular}{|c|c|c|c|c|}
\hline Sl. No. & Isolates designation & Identified as & Location & Accession No. \\
\hline 1 & S. rolfsii-Sr1 & Sclerotium rolfsii & Raichur & KT337415 \\
\hline 2 & S. rolfsii- $\mathrm{Sr} 2$ & Sclerotium rolfsii & Raichur & KT337409 \\
\hline 3 & S. rolfsii $-\mathrm{Sr} 3$ & Sclerotium rolfsii & Koppal & KT337424 \\
\hline 4 & S. rolfsii $-\mathrm{Sr} 4$ & Sclerotium rolfsii & Koppal & KT337411 \\
\hline 5 & S. rolfsii - Sr5 & Sclerotium rolfsii & Bellary & KT337413 \\
\hline 6 & S. rolfsii - Sr6 & Sclerotium rolfsii & Bellary & KT337425 \\
\hline 7 & S. rolfsii $-\mathrm{Sr} 7$ & Sclerotium rolfsii & Bellary & KT337414 \\
\hline 8 & S. rolfsii - Sr8 & Sclerotium rolfsii & Gadag & KT337423 \\
\hline 9 & S. rolfsii $-\mathrm{Sr} 9$ & Sclerotium rolfsii & Gadag & KT337420 \\
\hline 10 & S. rolfsii - Sr10 & Sclerotium rolfsii & Gadag & KT337419 \\
\hline 11 & S. rolfsii - Sr11 & Sclerotium rolfsii & Kalburgi & KT337421 \\
\hline 12 & S. rolfsii - Sr12 & Sclerotium rolfsii & Kalburgi & KT337412 \\
\hline 13 & S. rolfsii - Sr13 & Sclerotium rolfsii & Kalburgi & KT337426 \\
\hline 14 & S. rolfsii - Sr14 & Sclerotium rolfsii & Yadgir & KT337418 \\
\hline 15 & S. rolfsii - Sr15 & Sclerotium rolfsii & Chitradurga & KT337422 \\
\hline 16 & S. rolfsii - Sr16 & Sclerotium rolfsii & Chitradurga & KT337416 \\
\hline 17 & S. rolfsii - Sr17 & Sclerotium rolfsii & Tumkur & KT337410 \\
\hline 18 & S. rolfsii - Sr18 & Sclerotium rolfsii & Tumkur & KT337417 \\
\hline
\end{tabular}


Fig.1 Amplification product of Internal Transcribed Spacer (ITS) with ITS 1 and ITS 4 primers

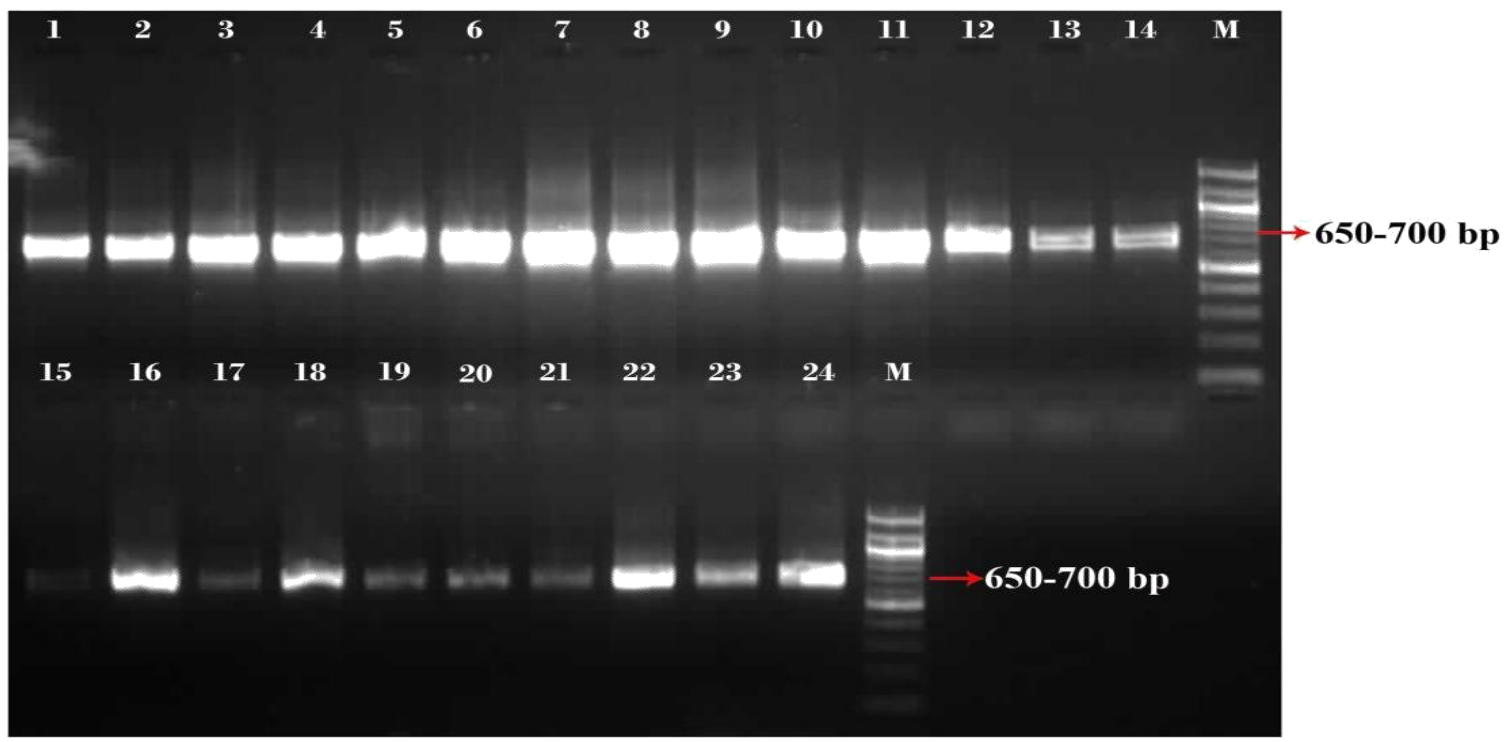

Fig.2 DNA profiling of $S$. rolfsii isolates banding on RAPD pattern using UBC-467, UBC-482, UBC-485 and UBC-489 primers
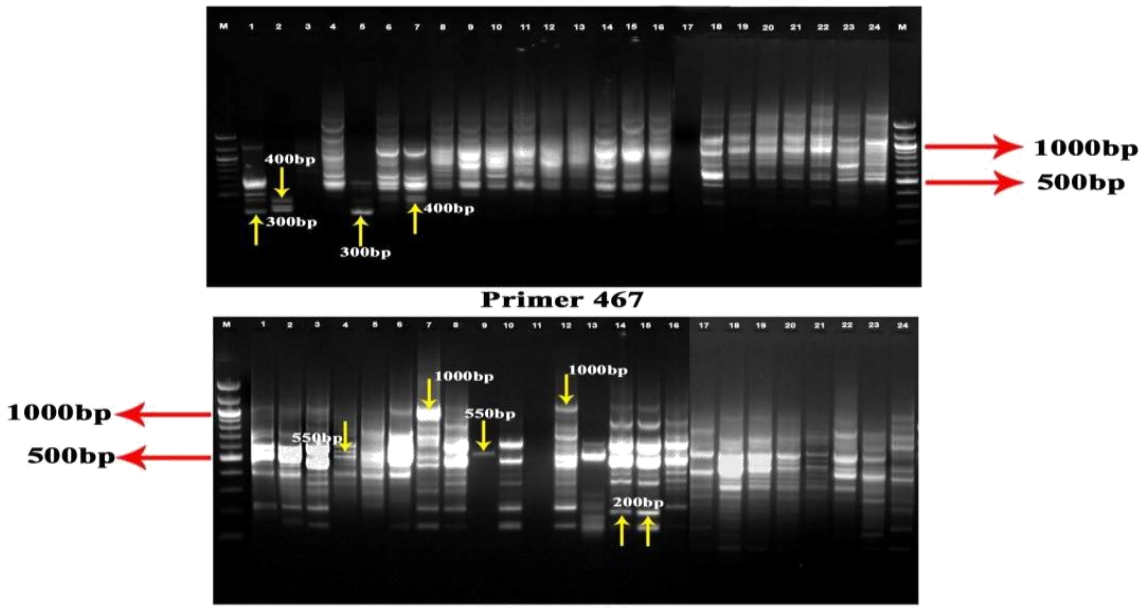

Primer 482

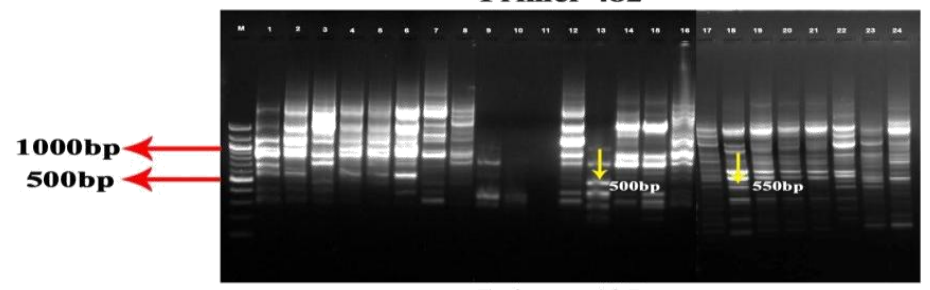

Primer 485

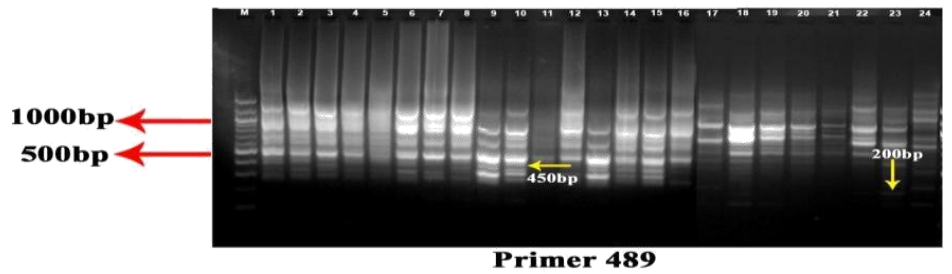

Primer 489 
Fig.3 Dendogram based on UPGMA cluster analysis obtained from multiple sequences of ITS region of Sclerotium rolfsii isolated from groundnut

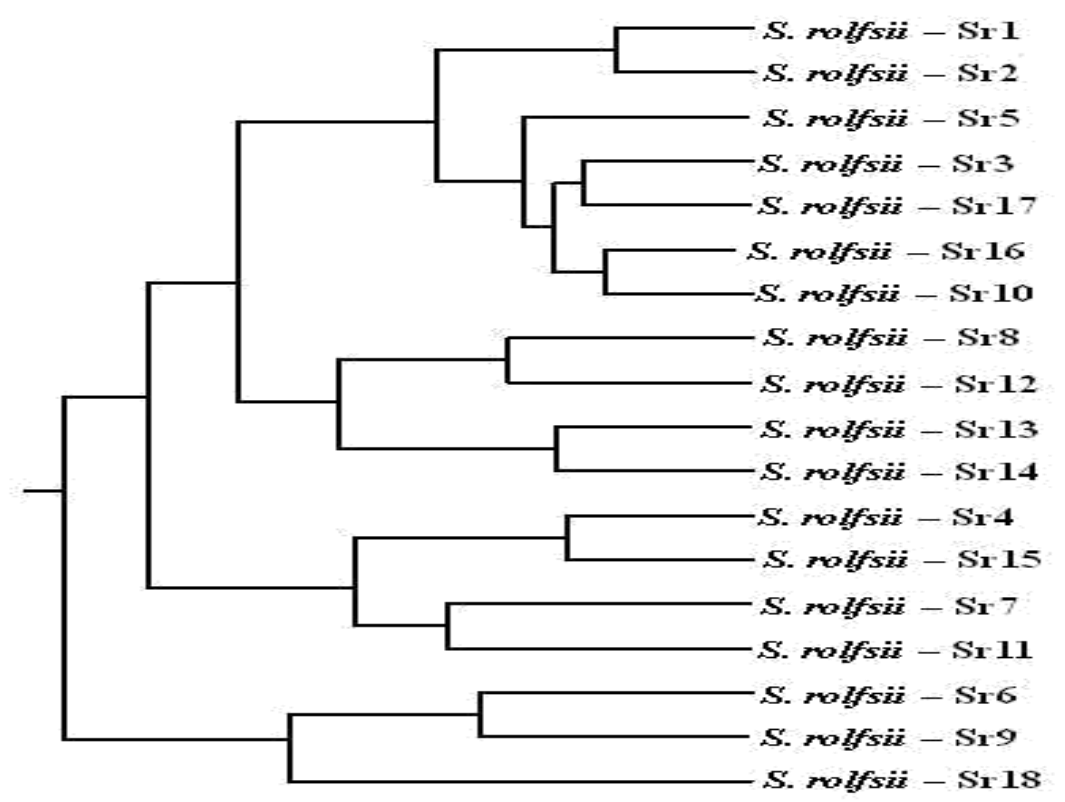

Fig.4 Hierarchical horizontal dendrogram of RAPD region showing clustering of 24 S. rolfsii isolates by DARwin V.6 software

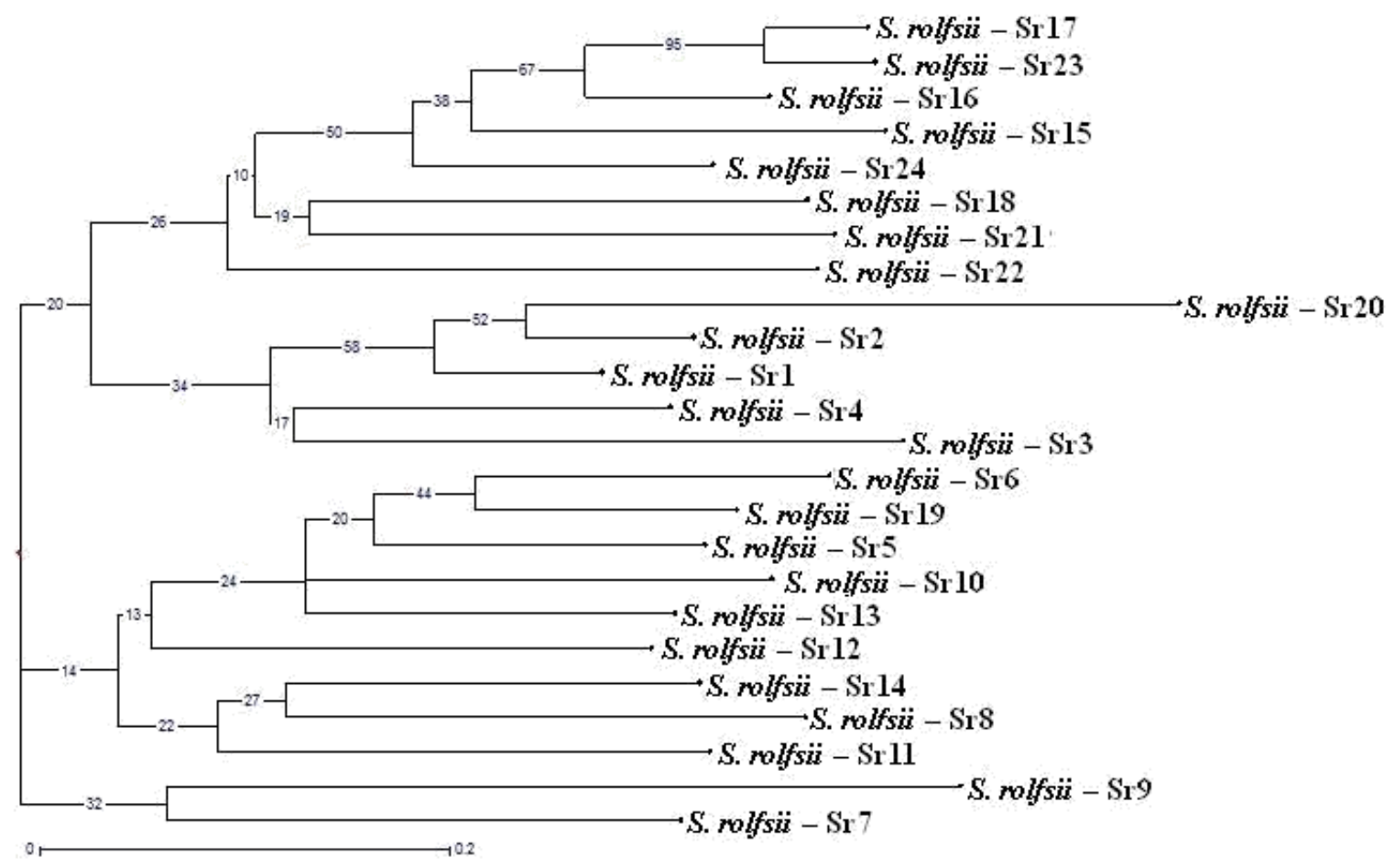


The genetic dissimilarity estimates for twenty four isolates were employed to generate dendrogram by using tree construction using the Unweighted Neighbourhood-joining method using the program DARwin 6.0 software (Fig 4). Based on the results obtained, all the twenty four isolates were grouped into three main clusters indicating there is genetic diversity in th isolates of $S$. rolfsii. Cluster I contained thirteen isolates, main cluster divided into two sub clusters, sub cluster I had eight isolates (Sr21, Sr20, Sr19, Sr18, Sr22, Sr24, Sr17 and $\mathrm{Sr} 23)$ and subcluster II had five isolates ( $\mathrm{Sr} 5$, $\mathrm{Sr} 2, \mathrm{Sr} 1, \mathrm{Sr} 6$ and Sr4). Main cluster II has two sub clusters, sub cluster I consisted of six isolates ( $\mathrm{Sr} 8, \mathrm{Sr} 3, \mathrm{Sr} 7, \mathrm{Sr} 12, \mathrm{Sr} 15$ and $\mathrm{Sr} 14)$ and in sub cluster II three isolates (Sr16, Sr10 and Sr13) were grouped. Cluster III consisted of two isolates ( $\mathrm{Sr} 9$ and $\mathrm{Sr} 11)$.

Among the twenty four isolates, four random primers viz., UBC-467, UBC-482, UBC-485 and UBC-489 generated reproducible polymorphism. Amplified products with all the primers showed polymorphic and distinguishable banding pattern indicating the genetic diversity among all the isolates of $S$. rolfsii. A total of 342 reproducible and scorable polymorphic bands ranging approximately as low as $150 \mathrm{bp}$ to as high as $2000 \mathrm{bp}$ were generated with four primers among 24 isolates characterized.

Based on the results obtained, all twenty four isolates were grouped into three main clusters (Fig. 4). Cluster I contains 13 isolates main cluster divided into two sub cluster, sub cluster I had eight isolates viz., Sr21, Sr20, Sr19, Sr18, Sr22, Sr24, Sr17, Sr23 and subcluster II had five isolates viz., $\mathrm{Sr} 5, \mathrm{Sr} 2, \mathrm{Sr} 1, \mathrm{Sr} 6$ and $\mathrm{Sr} 4$. Main cluster II has two sub cluster. The sub cluster I consists of six isolates $(\mathrm{Sr} 8, \mathrm{Sr} 3, \mathrm{Sr} 7$, $\mathrm{Sr} 12, \mathrm{Sr} 15$, and $\mathrm{Sr} 14)$ and in sub cluster II had three isolates ( $\mathrm{Sr} 16, \mathrm{Sr} 10$ and $\mathrm{Sr} 13)$ and cluster III consists of two isolates ( $\mathrm{Sr} 9$ and $\mathrm{Sr} 11$ ). Similarly, Prasad et al., (2010) studied the genetic variability among the virulent isolates of Sclerotium rolfsii by using molecular techniques like RAPD, ITS-PCR and RFLP.
The RAPD banding pattern reflected the genetic diversity among the isolates by formation of two clusters. A total of about 221 reproducible and scorable polymorphic bands ranging approximately as low as $100 \mathrm{bp}$ to as high as 2500 bp was generated with five RAPD primers.

ITS region of rDNA amplification with specific ITS1 and ITS4 universal primers produced approximately 650 to $700 \mathrm{bp}$ in all the isolates confirmed that all the isolates obtained were Sclerotium rolfsii. Le et al., (2012) studied the genetic and phenotypic diversity among the isolates of Sclerotium rolfsii isolated from groundnut crop. Based on ITS-rDNA sequence analyses, three distinct groups were identified among a total of 103 randomly selected $S$. rolfsii field isolates, with the majority of the isolates $(\mathrm{n}=90)$ in one ITS group. Rasu et al., (2013) studied genetic diversity of Sclerotium rolfsii from different hosts by using RAPD primers. RAPD banding patterns were established for 10 isolates of $S$. rolfsii using five random primers. Size of DNA fragments amplified by all five primers ranged from 100 bp to $>1 \mathrm{~kb}$ indicating polymorphism among $S$. rolfsii isolates.

\section{Acknowledgement}

The authors are very much thankful to ICRISAT, Asia centre, Patancheru for providing facilities to carry out molecular work to know the diversity of $S$. rolfsii isolates.

\section{References}

Adandonon, A., Aveling, T.A.S., Merwe, N.A., and Sanders, G., 2005. Genetic variation among Sclerotium isolates from Benin and South Africa, determined using mycelial compatibility and ITS rDNA sequence data. Aus. Pl. Path. 34: 19-25.

Anonymous, 2014. Status paper on oilseeds, National Mission on Oilseeds and Oil Palm (NMOOP), New Delhi. pp. 24-25.

Asghari, M.R., Mayee, C.D., 1991. Comparative efficacy of management 
practices on stem and pod rot of groundnut. Indian Phytopth. 44: 328-332.

Ghewande, M.P., Desai, S., Basu, M.S., 2002. Diagnosis and management of major diseases of groundnut, N. R. C. G., Junagadh. p. 11.

Harlton, C.E., Levesque, C.A., Punja, Z.K., 1995. Genetic diversity in Sclerotium (Athelia) rolfsii and related species. Phytopath. 85: 1269-1281.

Le, C.N., Mendes, R., Kruijt, M., Raaijmakers, J.M., 2012. Genetic and phenotypic diversity of Sclerotium rolfsii in groundnut fields in Central Vietnam. $\mathrm{Pl}$. Dis., 96: 389-397.

Okabe, I., Morikawa, C., Matsumoto, N., Yokoyama, K., 1998. Variation in Sclerotium rolfsii isolates in Japan. Mycosci. 39: 399-407.

Patil, D.S., 2009. Chemical management of fruit spot of pomegranate caused by Colletotricum gloesporioides Penz. and Sacc. Indian Phytopath. 62(2): 252-253.

Perez-Moreno, L., Olalde-Portugal, V., Vandemark, G.J., Martínezde, la Vega O., Martínez-Soriano, J.P., Vázquez Marrufo, G., Lara-Reyna, J., 2002. Genetic relationships among isolates of Sclerotium cepivorum Berk. based on RAPD analysis. Revista Mexicana de Fitopatologia 20: 187-192.

Perrier, X., Flori, A., Bonnot, F., 2003. Methods for data analysis. In: Hamon, P., Seguin, M., Perrier, X and Glazmann, J. C., (eds), Genetic diversity of cultivated tropical plants. Science Publishers, Inc and Cirad, Montpellier. pp. 31-63.

Prasad, S.D., Basha, S.T., Reddy, N.P.G.E., 2010. Molecular variability among the isolates of Sclerotium rolfsii causing stem rot of groundnut by RAPD, ITS-PCR and RFLP. Europ. Asian J. Biosci. 4: 80-87.

Rangaswami, G. and Mahadevan, A. 1999. Diseases of crop plants in India. Prentice Hall of India Pvt. Ltd., New Delhi. pp. 60-79.

Rasu, T., Sevugapperumal, N., Thiruvengadam, R., Ramasamy, S., 2013. Morphological and genomic variability among Sclerotium rolfsii populations. The Bioscan 8 (4): 1425-1430.

Sarma, B.K., Singh, U.P., Singh, K.P., 2002. Variability in Indian isolates of Sclerotium rolfsii. Mycologia 94: 10511058.

Saude, C., Melouk, H.A., Chenault, K.D., 2004. Genetic variability and mycelial compatibility groups of Sclerotium rolfsii [abstract], Phytopath., 94: S92.

Welsh, J., McClelland, M., 1990. Fingerprinting genomes using PCR with arbitrary primers. Nucleic Acids Research 18: 7213-7218.

White, T.J., Bruns, T., Lee, S., Taylor, J., 1990. Amplification and direct sequencing of fungal ribosomal RNA genes for phylogenetics: In: Inns, M. A., Gelfard, D. H., Sinisky, J. J. and White, T. J. (eds) PCR Protocols: A Guide to Methods and Applications. Academic Press, London. pp. 315-322.

\section{How to cite this article:}

Poornima, Gururaj Sunkad and Sudini, H. 2018. Molecular Variability among the Isolates of Sclerotium rolfsii Causing Stem and Pod Rot of Groundnut Collected from Karnataka, India. Int.J.Curr.Microbiol.App.Sci. 7(05): 2925-2934. doi: https://doi.org/10.20546/ijcmas.2018.705.341 